\title{
UMA NOVA ESPÉCIE DE BACCHARIS L. (ASTERACEAE-ASTEREAE) \\ DE MINAS GERAIS (BRASIL) ${ }^{1}$ \\ LEONARDO PAZ DEBLE ${ }^{2}$ ANABELA SILVEIRA DE OLIVEIRA ${ }^{3}$
}

\section{RESUMO}

Uma nova espécie de Asteraceae de Minas Gerais, é descrita e ilustrada: Baccharis dubia Deble \& An. S. de Oliveira.

Palavras-chave: Baccharis, nova espécie, Asteraceae, Astereae, Minas Gerais, Brasil.

\section{ABSTRACT}

A new species of Asteraceae from the State of Minas Gerais (Brazil) is described and illustrated: Baccharis dubia Deble \& An. S. de Oliveira.

Key Words: Baccharis, new species, Asteraceae, Astereae, Minas Gerais, Brazil.

\section{INTRODUÇÃO}

É apresentada uma nova espécie de Baccharis

L., conhecida, até o momento, unicamente pelo material típico, coletado na Serra do Caparaó (Minas Gerais). Singular dentro do gênero, Baccharis dubia parece demonstrar maior afinidade com Baccharis boliviensis (Wedd.) Cabrera e B. beckii Joch. Müller.

\section{DESCRIÇÃO}

1. Baccharis dubia Deble \& An. S. de Oliveira, sp. nov.

TIPO: Brasil, Minas Gerais, Serra do Caparaó, 2.500 m.s.m., arbusto com até $40 \mathrm{~cm}$, flores alvas, 19.IX.1941, A. C. Brade 16.970. Holotypus RB 45.893. Isotypus HDCF.

Suffrutex dense ramosus, $40 \mathrm{~cm}$ altus; caulibus superne dense foliosis, inferne subnudis, cicatricosis. Folia oblonga ad oblanceolata, 12-25 mm longa, 2-5 mm lata, concolora, sessilia, uninervia, subopposita ad alterna (internodiis usque 2 mm longis), glanduloso-punctulata, pilis conspersis, apice leviter acuta vel obtusa, basi attenuata. Capitula pedunculata (pedunculis pilosis, $0,5-3 \mathrm{~cm}$ longis), in corymbis terminalibus, 5-12-cephalus disposita. Involucrum campanulatum, 5-6,5 $\mathrm{mm}$ altum, $5-7 \mathrm{~mm}$ crassum. Receptaculo epaleaceo. Bracteis involucriacutis, 3-seriatis; externis pilosis, triangulatis vel ovatolanceolatis, 2,5-3,5 mm longis, 1-1,2 mm latis; mediis et intimis, lanceolatis, 4-5,5 mm longis, 0,8-1 mm latis. Flores dimorphi; marginales, 8-14, feminei, corolla crassa, tubulosa, 1,6-2,2 mm longa, apice breviter ligulata, ligula trilobata. Stylo 3-3,2 mm longo. Achaenia obovata, 1-1,5 mm longa, 5-costata, puberula, cum pilis geminis et papillis vestita. Pappi lutei, setae geniculatae, 2,5-3 mm longae. Flores disci, 40-60, mascula, corolla tubulosa, 4,2-5 mm longa, apice 5-lobata. Pappi lutei, setae 3-4 mm longae.

Subarbusto de até $40 \mathrm{~cm}$ de altura, densamente ramoso, folhoso no ápice e desprovido de folhas na base (Figura 1a). Folhas oblongas a oblanceoladas (12-25 mm de comprimento por 2-5 mm de largura), subopostas a alternas (entrenós de até $2 \mathrm{~mm}$ ), concolores, sésseis, uninérvias, pontuado-glandulosas, com tricomas esparsos, levemente agudas ou obtusas no ápice e atenuadas na base (Figura 1a'). Capítulos pedunculados (pedúnculos pilosos, de 0,5-3 cm), dispostos em corimbos terminais de 5-12-capítulos. Invólucro campanulado, de 5-6,5 mm de altura por 5-7 mm de diâmetro (Figura 1b). Receptáculo destituído de páleas. Brácteas involucrais agudas no ápice, dispostas em 3-séries: as externas, pubérulas, triangulares ou ovadolanceoladas (2,5-3,5 mm de comprimento por 11,2 $\mathrm{mm}$ de largura); as medianas e internas,

\footnotetext{
1 Artigo recebido em 22/08/2006 e aceito para publicação em 10/10/2006.

2 Biólogo, MSc., bolsista CAPES, doutorando do Programa de Pós-Graduação em Engenharia Florestal, Centro de Ciências Rurais, Universidade Federal de Santa Maria, CEP97105-900, Santa Maria (RS).anabela.biol@mail.ufsm.br

3 Bióloga, MSc., bolsista CAPES, doutoranda do Programa de Pós-Graduação em Engenharia Florestal, Centro de Ciências Rurais, Universidade Federal de Santa Maria, CEP 97105-900, Santa Maria (RS).deble.biol@ gmail.com
} 


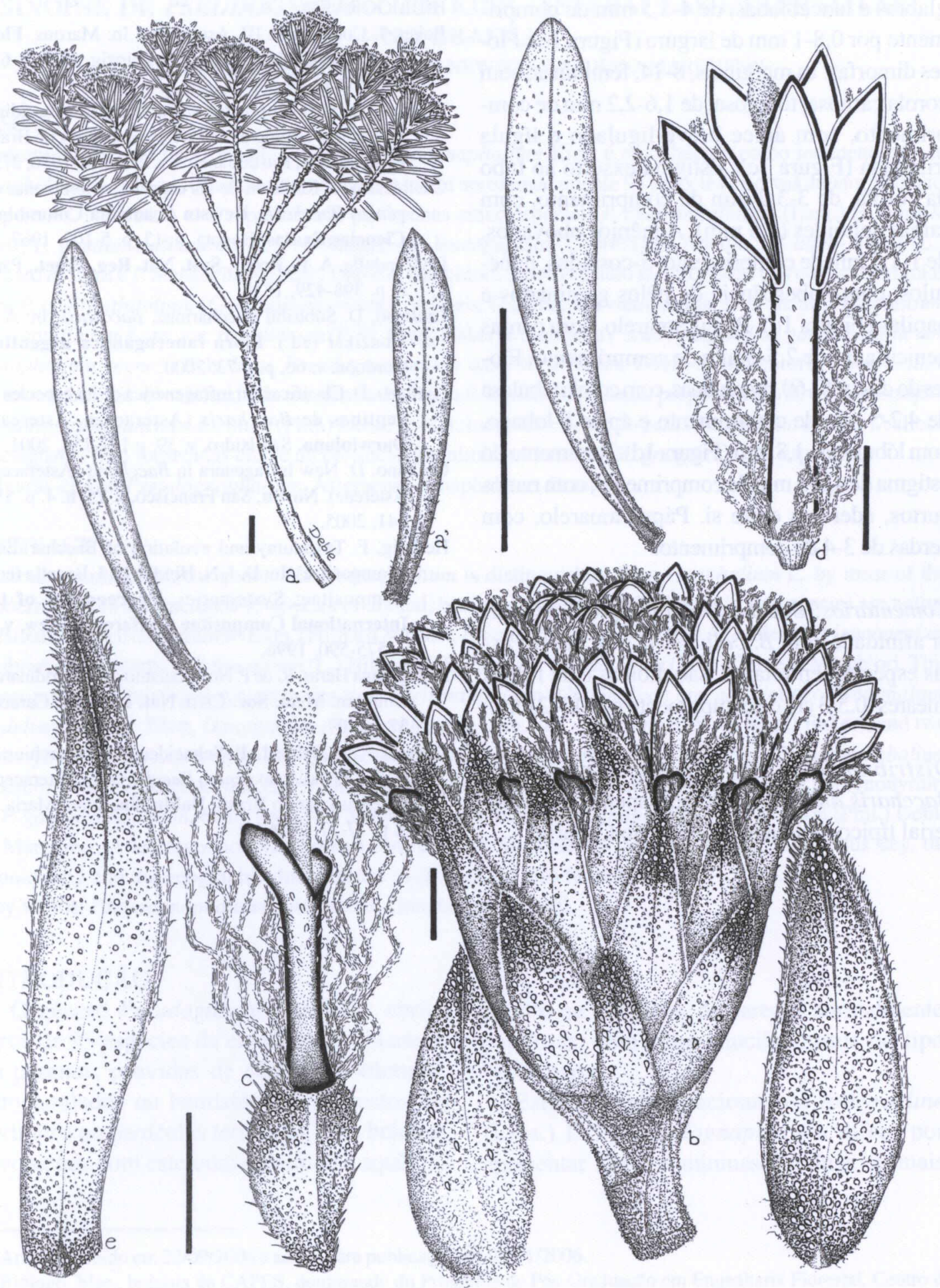

FIGURA 1 - Ramo de Baccharis dubia Deble \& An. S. de Oliveira (a). Folhas (a'). Capítulo (b). Flor feminina e aquênio (c). Flor masculina (d). Brácteas involucrais (e). (A. C. Brade 16.970). (a, a' = $1 \mathrm{~cm} ; \mathrm{b}, \mathrm{c}, \mathrm{d}, \mathrm{e}=1 \mathrm{~mm}$ ) 
glabras e lanceoladas, de 4-5,5 mm de comprimento por 0,8-1 mm de largura (Figura 1e). Flores dimorfas: as marginais, 8-14, femininas, com corola carnosa, tubulosa, de 1,6-2,2 mm de comprimento, com ápice breve-ligulado e lígula trilobada (Figura 1c). Estigma exserto ao tubo da corola, de 3-3,2 mm de comprimento, com ramas deltóides $(0,5 \mathrm{~mm})$. Aquênios obovados, de 1-1,5 mm de comprimento, 5-costados, pubérulos, com pubescência de pêlos geminados e papilas (Figura 1c). Pápus amarelo, com cerdas geniculadas de 2,5-3 mm de comprimento. Flores do disco, 40-60, masculinas, com corola tubulosa de 4,2-5 mm de comprimento e ápice 5-lobado, com lóbulos de 1,8 mm (Figura 1d). Rudimento do estigma de 4,5-5 mm de comprimento, com ramos curtos, aderidos entre si. Pápus amarelo, com cerdas de 3-4 de comprimento.

Comentários: Baccharis dubia apresenta maior afinidade com $B$. boliviensis e $B$. beckii; estas espécies, entretanto, são dióicas e de folhas lineares (0,5-3 cm de comprimento por 0,3-2 $\mathrm{mm})$.

Distribuição \& Habitat: Até o momento, Baccharis dubia é conhecido apenas pelo material típico, coletado na Serra do Caparaó.

\section{BIBLIOGRAFIA}

Baker, J. Compositae III. Asteroidae. In: Martius. Flora Brasiliensis. München, Wien, Leipzig, 1882. v. 6, n. 3, p. 1-132.

Barroso, G. M. Compositae - Subtribo Baccharidinae Hoffmann. Estudo das espécies ocorrentes no Brasil. Rodriguésia, Rio de Janeiro, v. 28, n. 40, 1976, 273p.

Cuatrecasas, J. Revisión de las especies colombianas del género Baccharis. Revista Academia Colombiana Ciencias Exatas, Bogotá, n. 13, p. 5-102. 1967.

De Candolle, A. P., Prodr. Syst. Nat. Reg. Veget., Paris, 6, p. 398-429, 1838.

Giuliano, D. Subtribu Baccharinae: Baccharis. In: A. T. Hunziker (ed.). Flora fanerogámica argentina, Córdoba, v. 66, p. 1-73, 2000.

Giuliano, D. Clasificación infragenérica de las especies argentinas de Baccharis (Asteraceae, Astereae). Darwiniana, San Isidro, v. 39, p.131-154, 2001.

Giuliano, D. New infragenera in Baccharis (Asteraceae, Astereae). Novon, San Francisco, v. 15, n. 4, p. 535$541,2005$.

Hellwig, F. Taxonomy and evolution of Baccharidinae (Compositae). In: D. J. N. Hind \& H. J. Beentje (ed.), Compositae: Systematics. Proceedings of the International Compositae Conference, Kew, v. 1, p. 575-590, 1996.

Malagarriga Heras, R. de P. Nomenclatura Baccharidinarum Omnium. Mem. Soc. Cien. Nat. La Salle, Caracas, 37, n. 107, 1977.

Oliveira, A. S., Deble, L. P., Schneider, A. A., Marchiori, J. N. C. Checklist do gênero Baccharis L. (AsteraceaeAstereae) para o Brasil. Balduinia, Santa Maria, n. 9, p. 17-27, 2006. 